\title{
ANÁLISE DAS METODOLOGIAS DE INTERVENÇÃO PSICOSSOCIAL EM GRUPO DE HOMENS AUTORES DE VIOLÊNCIA CONJUGAL
}

\author{
ANALYSIS OF PSYCHOSOCIAL INTERVENTION METHODOLOGIES \\ IN GROUP OF MEN PERPETRATORS OF CONJUGAL VIOLENCE
}

\begin{abstract}
Resumo
Mediante o fenômeno da violência contra a mulher e as prerrogativas da Lei Maria da Penha (Lei no 11.340), este artigo teve como objetivo analisar os documentos que relatam as metodologias de intervenção social da Psicologia e Serviço Social no projeto de extensão "Educação e Atenção Psicossocial a Homens Autores de Violência Conjugal" em Manaus, Amazonas. Trata-se de Pesquisa Documental, com enfoque qualitativo. Os resultados apontaram que as metodologias foram consideradas inovadoras na região norte, ao contemplarem as relações socioculturais, utilizarem a linguagem como principal instrumento de dialogicidade e responsabilização, potencializarem o cuidado de si e do outro na conjugalidade e apresentarem uma alternativa de assistência. Concluiu-se que as metodologias de intervenção oportunizaram a reflexão das práticas sociais e do fazer profissional, considerando a complexidade e dinamicidade do fenômeno psicossocial.
\end{abstract}

Palavras-chave: Gênero. Psicologia. Homens. Violência conjugal.

\begin{abstract}
With the phenomenon of violence against women and prerogatives of the Maria da Penha Law (Law 11,340), this paper analyzed the methodologies of social intervention of the extension project "Education and Psychosocial Care for Men Authors of Spousal Violence" in Manaus / Amazonas. The project supported the Education and Offender Accountability Secretariat of State of Amazonas Justice, in partnership with the Federal University of Amazonas. The tour was named "Group of meaning in Construction". These methods were analyzed by Documental research with qualitative approach. The methodologies were considered innovative in the northern region in contemplating the sociocultural relations, using language as the main instrument of dialog and accountability, potentiating care of self and other in marital and present an alternative service. To analyze the effectiveness of methodologies favors the reflection of social practices and professional make considering the complexity and dynamics of psychosocial phenomenon.
\end{abstract}

Keywords: Gender, Psychology, Men, Spousal violence.

\footnotetext{
André Luiz Machado das Neves

Universidade do Estado do Amazonas - UEA.

E-mail: andre_machadostm@hotmail.com

Fabiane Aguiar Silva

Universidade Federal do Amazonas - UFAM.

E-mail: fabianeaguiarpsi@hotmail.com

Iolete Ribeiro Silva

Universidade Federal do Amazonas - UFAM.

E-mail: iolete.silva@gmail.com

Thiago Silva dos Santos

Universidade Federal do Amazonas - UFAM.

E-mail: thsantos90@gmail.com

Fernanda Priscilla Pereira Calegare

Tribunal de Justiça do Estado do Amazonas.

E-mail: naiade89@gmail.com
} 
Diante da necessidade de cumprimento das prerrogativas da Lei Maria da Penha (Lei no 11.340), que prevê a criação de programas de atendimentos a homens ou mulheres lésbicas autores de violência conjugal contra a mulher, a Universidade Federal do Amazonas (UFAM), em parceria com a Secretaria de Estado da Justiça (SEJUS), executou uma estratégia de intervenção psicossocial com base no projeto "Educação e Atenção Psicossocial a Homens Autores de Violência Conjugal". O projeto, implementado por meio de intervenções junto ao Serviço de Educação e Responsabilização do Agressor (SARE), desenvolvido pelo Departamento de Direitos Humanos da Secretaria de Estado da Justiça e Direitos Humanos do Amazonas (SEJUS), era voltado ao atendimento a grupos de homens autores de violência conjugal contra a mulher que foram denunciados.-

As intervenções contaram com profissionais Psicólogos, Assistentes Sociais, uma Advogada e estagiários que, em conjunto, criaram o "Grupo de Sentidos em Construção". A equipe que constituiu esse grupo, inicialmente, reuniu-se para estruturar os atendimentos e preparar os trabalhos de intervenções no grupo, por meio de atendimentos individuais, executados por dupla de técnicos da equipe do SARE e UFAM (Psicologia e Serviço Social).

As estratégias de intervenção em grupo exigem uma rigorosa análise, para que, consoante Carvalhosa, Domingos e Sequeira (2010), possibilitem a compreensão dos processos de trabalho com determinados grupos e sua efetividade na transformação social pelos atores. As estratégias de intervenção, com foco na elaboração de programas com características de apoio na responsabilidade individual, orientam-se por problemas e soluções. Nessa acepção, o fortalecimento do sujeito pode ser suscitado com o enfoque na capacidade e na melhoria de suas competências, de forma que possa permitir-lhe desenvolver estratégias para a resolução dessas questões. Esses autores consideram importante a avaliação, vislumbrando identificar se os indicadores alcançaram os objetivos da intervenção e se possibilitaram novos conhecimentos.

Nesse âmbito e considerando a complexidade que envolve a violência conjugal, entende-se a necessidade de olhar com maior atenção para esse fenômeno e também para o estudo e a criação de métodos interventivos voltados para a educação e atenção psicossocial, que atinjam de maneira efetiva tal público (Williams, 2001; Silva, Silva, Tavares, Oliveira, Neves, Silva e Oliveira, 2015).

A violência conjugal foi inicialmente caracterizada por agressões físicas e psicológicas que aconteciam na privacidade do lar, sendo considerada de domínio privativo e íntimo do casal ou dos pares. Todavia, a partir dos anos 80, a violência entre cônjuges passou a ser assumida como uma questão social (Lamoglia e Minayo, 2009).

A representação do homem autor de violência conjugal contra a mulher revela a conjunção de um histórico de reações inadequadas ao estresse, abuso prévio ou incapacidade psicológica de se relacionar (Cortez, Padovani e Williams, 2005). Segundo Lamoglia e Minayo (2009), geralmente os homens reconhecem apenas os excessos em sua agressividade e não avaliam sua agressão como um ato corretivo. Entretanto, costumam dizer que avisam a mulher sobre o desagrado de suas atitudes e, não sendo obedecidos, batem, atribuindo à mulher a responsabilidade pelo seu descontrole. Tais perfis caracterizam a mulher como vítima e o homem como agressor, dado que exige maior reflexão, principalmente da dimensão das relações de gênero (Falcke, Oliveira, Rosa e Bentancur, 2009).

Tendo em vista as contribuições de Scott (1988), ao abordar gênero como uma organização social da diferença sexual, discute-se que isso não significa que o gênero reflita ou produza diferenças físicas fixas e naturais entre mulheres e homens. Entende-se, mais propriamente, que o gênero é o conhecimento que estabelece significados para diferenças corporais com base na cultura. Reafirmam essa ideia, os pesquisadores Alves, Silva, Ernesto, Lima e Souza (2011), ao argumentarem: “(...) devem ser entendidas como significados culturais atribuídos às diferenças sexuais, e que, à medida que são construídas e perpassadas culturalmente, são também referências para o modo de ser e se relacionar." (p. 153)

Frente a essas questões, é possível perceber, nos relatórios analisados, que os homens inseridos no "Grupo Sentidos em Construção" experimentaram ressignificações na compreensão dos determinantes de suas condutas e nos modos de lidar com os outros e consigo mesmos. Também avaliaram que seriam capazes de promover diálogos pautados no reconhecimento e no cuidado dos direitos e desejos de cada pessoa. Diante disso, metodologias foram 
sendo construídas durante o processo de intervenção com base nos discursos, nos sentidos subjetivos construídos e nas relações estabelecidas no grupo, para possibilitar intervenções específicas frente a estes homens autores de violência.

Sob a perspectiva da psicologia sócio-histórica, busca-se contribuir, de forma crítica, com o fomento dos estudos sobre metodologias interventivas que possam concorrer para a prevenção da violência conjugal contra a mulher, de modo que as discussões acerca de novas abordagens do fenômeno psicossocial possam gerar intervenções implicadas com as dimensões éticas e políticas do fazer social e da psicologia.

Apresenta-se, nessa acepção, a partir da análise de relatórios de atividade interventiva junto a homens autores de violência conjugal contra a mulher, a avaliação das metodologias construídas nesse contexto. $\mathrm{O}$ objetivo deste artigo é analisar os documentos que relatam as metodologias de intervenção social da Psicologia e Serviço Social no projeto de extensão "Educação e Atenção Psicossocial a Homens Autores de Violência Conjugal" em Manaus, Amazonas.

\section{Método}

A pesquisa foi do tipo documental, com enfoque qualitativo. As fontes foram os relatórios do projeto elaborados pelos estudantes de Psicologia e o relatório de observação do Serviço Social, vinculado ao projeto de extensão Educação e Atenção Psicossocial a Homens Autores de Violência Conjugal, com o apoio da Secretaria de Justiça do Amazonas. O enfoque teórico partiu da abordagem da psicologia sócio-histórica nos processos de violência conjugal contra a mulher e relações de gênero.

Realizou-se, via e-mail, telefone e/ou contatos pessoais dos profissionais e acadêmicos participantes do projeto de intervenção, a solicitação dos relatórios por eles elaborados após a conclusão das intervenções do projeto. Para formalizar a comprovação de entrega voluntária de tais documentos pelos profissionais e acadêmicos, elaborou-se um protocolo de recebimento.

Posteriormente, após a impressão e/ou produção de cópias, foi realizada a leitura flutuante dos relatórios com foco na metodologia de intervenção. Na sequência, os relatórios foram organizados para possibilitar a seleção dos aspectos recorrentes e distintos. Em seguida, após a identificação dos eixos norteadores e das categorias com base nos aspectos mais representativos contidos nos relatórios, compuseram-se tabelas nas quais esses conteúdos foram sendo registrados, de modo a possibilitar a construção das primeiras hipóteses.

Para analisar e identificar se a metodologia utilizada alcançou os objetivos da intervenção e se possibilitou a homens autores de violência conjugal novas vivências de intervenção, os relatórios foram analisados segundo a visão dialética de homem, construída por Vigotski (1996), que se apresenta como um meio possível para análise, posto que esse pressuposto teórico considera a dinamicidade com que os sujeitos apropriam-se e interferem em sua realidade, que é negada e afirmada de maneira concomitante, como foi e continua sendo a constituição dos discursos sobre a violência conjugal contra a mulher no trajeto sócio-histórico das relações de gênero.

Para trabalhar com os conteúdos selecionados, recorreu-se à análise qualitativa de conteúdo (Flick, 2009) na perspectiva da psicologia sócio-histórica. Tal escolha permitiu a operação de classificação dos conteúdos segundo as discussões de gênero sobre a violência conjugal contra a mulher constantes na referida abordagem teórica.

\section{Resultados e Discussão}

As metodologias interventivas desenvolvidas pelos profissionais de Psicologia e Serviço Social, foram criadas em conjunto com os homens autores de violência conjugal, possibilitando uma aproximação maior com a problemática. Tal processo caracterizou a intervenção por atributos psicossociais, proporcionando um espaço de reflexão e de diálogo para o desenvolvimento de novas habilidades para esses homens autores de violência conjugal contra a mulher. $\mathrm{O}$ quadro 1 expõe as intervenções utilizadas no projeto, segundo a ordem em que foram sendo criadas juntamente com os homens autores de violência. 


\begin{tabular}{|c|c|}
\hline Metodologias Interventivas & Objetivos \\
\hline $\begin{array}{l}\text { Discutindo processos de } \\
\text { subjetivação }\end{array}$ & $\begin{array}{l}\text { Propunha discussões sobre os sentidos construídos pelos homens que se implicavam nas } \\
\text { relações com as parceiras. Discutia-se se a reprodução de tais sentidos desfavorecia as relações } \\
\text { e refletiam os possíveis sentidos para a quebra de ciclos de relações com constantes repetições } \\
\text { de sofrimento e violência, bem como para a vivência mais prazerosa com o par. }\end{array}$ \\
\hline Questionando os padrões & $\begin{array}{l}\text { Tentativa de discutir se o gênero é necessariamente uma função social (uma performance } \\
\text { padronizada e fixa) que somente precisa ser reproduzida ou pode ir se construindo e se } \\
\text { transformando pelos discursos nas relações. }\end{array}$ \\
\hline Práxis & $\begin{array}{l}\text { Usava-se o quadro branco para criar esquemas de análise de uma vivência e a reprodução } \\
\text { de sentidos na mesma. Além disso, os homens poderiam ainda ir delineando no quadro um } \\
\text { esquema de como possivelmente estavam conseguindo construir um novo sentido. }\end{array}$ \\
\hline A violência construída & $\begin{array}{l}\text { Utilizava os variados sentidos de violência com o objetivo de discutir a violência como uma } \\
\text { construção que envolve a história, a educação, as relações e as demais dimensões. Para tanto, } \\
\text { precisava ser considerada e refletida. }\end{array}$ \\
\hline Refletindo o_acordo & $\begin{array}{l}\text { Refletiam acerca do acordo cotidiano construído pelo casal, uma vez que a convivência é um } \\
\text { dos principais desafios. O grupo abordou os aspectos do acordo que um casal estabelece todos } \\
\text { os dias durante a convivência, ressaltando as negociações e os papéis assumidos que favorecem } \\
\text { ou não a relação. }\end{array}$ \\
\hline $\begin{array}{l}\text { Construção do "Catálogo da } \\
\text { Cidadania" }\end{array}$ & $\begin{array}{l}\text { Denominado "Catálogo da Cidadania" foi elaborada para auxiliar os participantes no exercício } \\
\text { de seus direitos sociais. O catálogo possuía endereços e telefones e sugeria instituições de } \\
\text { acesso à cidadania nas mais diversas dimensões sociais. }\end{array}$ \\
\hline
\end{tabular}

Quadro 1. Metodologias interventivas e objetivos

Constatou-se que, no ano de 2011, foram utilizadas seis metodologias no SARE. Os relatórios permitiram constatar-se que as metodologias focaram o discurso, considerando que os profissionais envolvidos no processo interventivo utilizaram a abordagem do construcionismo social, segundo a qual, por meio de um conceito de prática educacional, alcança-se a produção de sentidos.

Os citados profissionais basearam-se em Zuriff (1998), por compreenderem que a seleção da teoria se baseia na crença de que, ao invés de descobrir uma realidade objetiva e independente, o ser humano constrói conhecimento em suas relações. Desse modo, não há uma realidade estática e objetiva a ser descoberta. Os seres humanos constroem seu próprio conhecimento, bem como constroem as teorias a respeito do funcionamento do mundo ativamente, mas sempre na interação social.
Pôde-se constatar, no texto dos relatórios, que os profissionais associaram as metodologias ao conceito de prática educacional libertadora, que pode ser entendido como todo desenvolvimento pessoal. Desse modo, tendo em vista que, para a concepção histórico social, a educação é entendida como um processo social e, portanto, um ato coletivo (Freire, 2008), discute-se que, para o aperfeiçoamento das capacidades individuais, é preciso investir-se em educação e na construção coletiva de novas formas de se relacionar com o mundo e consigo mesmo.

Nos relatórios da Estratégia de Educação e Atenção Psicossocial aos Homens, verificou-se que os profissionais recorreram às contribuições de Freire (2008), no que concerne à compreensão do educador de que ninguém ensina ninguém e muitos menos conscientiza alguém; os 
homens, com base em um processo de interação, aprendem e ensinam juntos, fazendo da educação um investimento nas potencialidades humanas, compreendidas como potencialidades do gênero humano. Compreende-se, portanto, que educação, como única forma de produção/ reprodução/transformação dessas potencialidades e, portanto, de produção/reprodução/transformação do próprio homem, torna esse ser humano dotado de práxis. Isto quer dizer que esse ser humano, consciente de sua ação sobre a natureza - produto e produtor -, transforma-a e cria, coletivamente, um ambiente não natural ou sociocultural.

No caso do grupo objeto dos relatórios estudados, a reflexão, o exercício de aprendizagem social e a interação com o outro na prática interventiva com o grupo foram elaborados com base nas demandas trazidas pelo discurso dos homens autores de violência, de tal modo que tornou dinâmico o processo de desenvolvimento dessa prática interventiva, conforme revelaram os relatórios analisados.

Essa prática, portanto, evidenciou a importância da linguagem nesse processo, pois, como ressalta Vigotski (1996), o papel a ela atribuído volta-se para a construção da consciência e a formação do sujeito, intermediado pela interação com os outros. Isto é, a linguagem possibilita ao ser humano transformar a si mesmo e ao mundo ao seu redor.

Partindo deste preceito, reflete-se, com base nos relatórios do grupo, que os homens autores de violência conjugal tiveram a oportunidade, por meio do discurso, de elaborar novos sentidos para as suas relações. Bakhtin (1997) cita que o grupo se torna para o ser humano uma prática social, cuja realidade material, a língua, constituise como desenvolvimento e evolução contínua, constituído pelo fenômeno social da interação verbal. Assim, no caso do grupo objeto dos relatórios em estudo, trata-se de um processo que envolve não apenas a presença física dos homens autores de violência, mas também o seu tempo histórico e o espaço social de interação.

Para o desenvolvimento da prática em foco, ficou evidente a necessidade de realizar atendimentos individuais pré-grupo, entendidos como intervenções de preparação do usuário e do mediador especificamente para os homens do grupo. Esses atendimentos possibilitaram ao profissional compreender o homem e os sentidos sobre sua situação com sua companheira, promovendo um acolhimento inicial e preparando-o para ingressar no grupo de intervenção.

Os relatórios indicaram que essa proposta pode ser considerada uma iniciativa pioneira no trabalho que envolve a violência conjugal no estado do Amazonas. Em outras localidades, como no Rio de Janeiro, já existem atividades voltadas para a violência de gênero, desenvolvidas pelo Instituto Noosfera (NOOS).

As metodologias utilizadas possibilitaram verificar-se que o homem precisa ser compreendido como um ser único e dotado de práxis. Segundo Vigotski (1996), ele exerce a dupla função de transformador e transformado, isto é, é moldado pela cultura que ele próprio cria e pelo que o envolve.

Deste modo, Vigotski (1996) aponta que os signos são instrumentos psicológicos e mediadores internos que o homem utiliza para gerir suas próprias ações psicológicas e de outros indivíduos. Apresenta-se também como resultado, a assertiva de que as metodologias em destaque, quando utilizadas no SARE, buscaram compreender o ser humano de uma maneira tal, que pudesse possibilitar o desenvolvimento e a aprendizagem de seus atos e sobre si na relação com os outros e consigo mesmo.

Pode-se afirmar, com base nos relatórios pesquisados, que as metodologias de intervenção foram constituídas de maneira sistematizada (à medida que se desenvolviam) e caracterizaram-se por atendimentos de pré-grupo, encaminhamento e ingresso dos homens autores de violência conjugal no grupo.

De acordo com o relatório de estágio dos estudantes de psicologia, os homens atendidos estavam cientes do compromisso que o Programa SARE assumia com eles, que consistia em proporcionar-lhes um espaço onde pudessem discutir seus problemas, buscando novas formas de entendê-los e de enfrentá-los. Os relatórios consideram também o que esses homens já estavam fazendo de positivo para enfrentar os seus problemas, e ressaltaram a capacidade de dialogar que estavam desenvolvendo. Nesse processo, o diálogo mostrou-se um importante instrumento de enfrentamento da violência e de aprender a cuidar de si e da companheira.

Ainda com base nos registros dos relatórios, pôde-se perceber que as intervenções trabalharam com o diálogo, visando compreender o processo inicial e promover tomadas de consciência no homem sobre suas 
potencialidades, fazendo com que ele percebesse o que possuía de melhor. Com isso, buscava fazer com que ele fosse o próprio mediador dos conflitos e encontrasse resoluções relacionais para seus problemas. Tal dado, revelado nos relatórios, aproxima-se dos resultados da pesquisa desenvolvida por Aguiar (2011), que também buscou, com base em dinâmicas sistematizadas em catorze sessões, o encontro grupal follow-up baseado em um grupo focal centralizado no discurso. $\mathrm{O}$ autor constatou que esse recurso contribuiu para a melhoria da convivência familiar e em outros contextos sociais após a participação nas intervenções grupais.

De acordo com Vaughn, Schumm e Sinagub (1996), esse tipo de trabalho faz com que o grupo identifique as percepções que ocorrem entre eles, bem como os sentimentos, atitudes e ideias dos integrantes a respeito de um determinado assunto proposto, promovendo e favorecendo discussão, interação grupal e troca de reflexões compartilhadas, com base nos conteúdos referentes aos temas, num processo semelhante ao que está descrito nos relatórios estudados.

Fica evidente, portanto, que as metodologias utilizadas no SARE buscavam auxiliar o homem autor de violência conjugal a alcançar o protagonismo de seus sentimentos e valores, bem como responsabilizar-se por seus comportamentos e atos, além de mais capacitado para dialogar e se colocar no lugar do outro, para cuidar de si e, consequentemente, dos outros.

\section{A Linguagem como Instrumento para o Manejo de Demandas dos Homens Autores de Violência Conjugal}

Sobre metodologias interventivas e suas ações de manejo com homens autores de violência, pesquisas revelam que algumas técnicas utilizadas no projeto do SARE foram semelhantes às utilizadas anteriormente em projetos interventivos desenvolvidos em estados como Rio de Janeiro, Recife e Salvador (Acosta, Andrade Filho e Bronz, 2004; Diniz, Lopes, Gesteira, Alves e Gomes, 2003; Freitas e Cabrera, 2011).

No estado do Amazonas, elas ganharam um destaque, podendo ser consideradas um trabalho inovador e pioneiro, ao enfatizarem a processualidade subjetiva do sujeito. A construção do diálogo igualitário entre os gêneros, bem como a construção desse homem que favoreça a sua responsabilidade mediante seus atos e frente à realidade e a si, foram ferramentas imprescindíveis à intervenção (Silva, Silva, Tavares, Oliveira, Neves, Silva e Oliveira, 2015). No caso da pesquisa realizada, o projeto não utilizou maneiras impositivas nem punitivas para obrigar a participação dos homens, uma vez que não favoreceriam no processo interventivo proposto pela intervenção.

Sobre o manejo que ocorreu no Projeto Interventivo, foi possível identificar-se, nos relatórios analisados, que, ao reconhecerem a causa de suas ações violentas, expressas no grupo por meio do discurso, os homens autores de violência implicavam-se no processo, de modo a se colocarem como responsáveis pelos seus atos e escolhas. Além disso, apontavam a necessidade do aprimoramento da comunicação e da capacidade de dialogar e de se perceberem no lugar do outro, de modo a lhes favorecer o cuidado com o outro e consigo mesmos.

Fica evidente, portanto, a importância da linguagem para o aperfeiçoamento e as melhorias no que se refere à ênfase na linguagem possibilitada pela comunicação, fazendo com que o homem seja construtor e construído por suas interações com o próximo, tal como propõe Vigotski (1996). Ao apontar a linguagem como uma importante ferramenta mediadora nas experiências de interação do homem com o próprio ambiente, esse autor afirma que o homem muda a forma social e o seu nível de desenvolvimento cultural. Para Santos (2004), a linguagem pode ser vista como uma aprendizagem e como uma construção da consciência, ao se tornar parte indispensável para a formação do sujeito, que é intermediada pela interação com o ambiente.

Nesta pesquisa, as transformações vivenciadas pelos homens autores de violência conjugal podem ter se dado pelo auxílio encontrado na interação proporcionada no grupo pelos profissionais. Ao se apropriarem do problema e envolverem os participantes no processo interventivo, eles contribuíram com os homens na transformação do modo de compreenderem a si mesmos e ao mundo.

Segundo Pino-Sigardo (2000), “(...) diferentemente dos animais, sujeitos aos mecanismos instintivos de adaptação, os seres humanos criam instrumentos e sistemas de signos cujo uso lhes permite transformar e conhecer o mundo, comunicar suas experiências e desenvolver novas funções psicológicas" 
(p. 39). O exemplo dos homens participantes do grupo, que experimentaram transformações pessoais a partir das vivências grupais, deixa claro, portanto, que as funções psíquicas humanas têm origem nos processos sociais.

Partindo de tal perspectiva, compreende-se a masculinidade como uma construção social que, para Oliveira (2004), é o resultado de complexas elaborações culturais. Assim, pode ser compreendida como um processo histórico-cultural. Esse autor chama a atenção para a masculinidade como um espaço simbólico de sentidos estruturantes no qual se modelam atitudes, comportamentos e emoções a serem seguidos. Assim, aqueles que seguem tais padrões não são apenas atestados como homens, mas também não são questionados por outros que compartilham desses símbolos, isto é, pessoas do gênero masculino e feminino.

Tal compreensão pode ser encontrada em um dos relatórios analisados, quando menciona que um homem participante do projeto interventivo relatou que tais modificações de sentidos estavam sendo introduzidas em seu modo de lidar com o mundo e consigo. Assim, buscou dialogar com sua parceira acerca de suas relações, bem como sobre como estavam lidando um com o outro, porém esse diálogo foi interrompido por sua parceira, que criticou o seu comportamento e questionou a sua orientação sexual. Esse relato evidencia que existem características masculinas implícitas na própria construção da feminilidade, que podem dificultar as ressignificações esperadas dos homens autores de violência conjugal.

Ressalta-se que, no caso em estudo, o uso da técnica "Discutindo processos de subjetivação" proporcionou o desenvolvimento de novas funções psicológicas no Projeto Interventivo. Os relatórios evidenciaram que essa técnica buscava discutir a reprodução de um sentido que era acordado nas relações com os parceiros e que não oportunizava a construção de outros sentidos, perpetrando, assim, ciclos de relações com constantes repetições de sofrimentos e violência. Esse aspecto foi discutido com os homens autores de violência por meio de músicas que retratavam, de forma indireta, constantes violências e formas reducionistas de enxergar as relações conjugais. Esses homens, ao identificar-se com as letras das músicas e as discutirem, acabavam por questionar as estereotipias nelas propostas e, com isso, transformavam os significados que possuíam.
Esse resultado da pesquisa é explicado por Vigotski (1996), ao assegurar que a identificação, por meio do discurso, pode ser entendida como um sistema articulado de signos que é construído socialmente ao longo da história, porém esses signos são mutáveis e adquirem sua significação concreta no contexto da interlocução. Desta forma, o homem é reconstituído internamente e vai se aproximando do que já foi desenvolvido pela espécie e, consequentemente, passa a contribuir para a criação de novos instrumentos e signos. Assim, esse processo de interiorização e apropriação é mediado pelas interações e intercomunicações sociais, nas quais a linguagem torna-se fundamental.

Desse modo, no caso da pesquisa realizada, fica evidente que, com a percepção de si e de seus atos propiciadas pelo grupo, os homens autores de violência desenvolveram habilidades no que se refere à construção de suas masculinidades, enfrentando as dificuldades de se desvincularem dos padrões de masculinidade construídos sócio-historicamente. À medida que esse processo foi se desenvolvendo, esses homens iam se desprendendo das proposições de relações de gênero desiguais e favoreciam as relações de gênero desprovidas de sofrimento, valorizando a responsabilização e reconhecendo seus próprios desejos e direitos para lidar consigo e com os outros.

Esse modo de relacionar-se consigo e com o mundo, por meio da interação com o outro, favorece o aprendizado, como entende Smolka (2000), para o qual, a “(...) aprendizagem significativa implica na interação entre conhecimentos prévios e novos conhecimentos, um processo no qual estes passam a ter significados psicológicos e os primeiros podem adquirir novos significados". (p. 50)

Diante do exposto, destaca-se a dinamicidade do processo desenvolvido pelos profissionais inseridos no projeto, uma vez que fizeram da dinâmica interventiva algo construído juntamente com os homens autores de violência conjugal, possibilitando maior aproximação com a realidade desse fenômeno.

Os relatórios mostraram que foi observada a necessidade de se fazer um trabalho que complementasse as propostas de leis, como a Lei $\mathrm{n}^{\circ} 11.340$, para coibir a violência de gênero e criar programas de atendimentos a homens ou mulheres lésbicas autores de violência conjugal contra a mulher. 
Assim, o projeto buscou o cumprimento das prerrogativas da citada lei, possibilitando que os homens autores de violência conjugal participassem do projeto, uma vez que esta adesão influenciaria de maneira positiva em seu processo jurídico. Foi observado que este fato não interferiu nos resultados e, ao contrário, influenciou de modo positivo num melhor desenvolvimento da prática interventiva.

Desta forma, observou-se, nos relatórios avaliados, que os objetivos propostos pelo Projeto Interventivo tornaram-se mais abrangentes durante o seu desenvolvimento, uma vez que os homens autores de violência acolheram a proposta e permitiram-se vivenciar essa nova metodologia de enfrentamento da violência conjugal. Além disso, durante a intervenção, mostraramse dispostos e mudar essa perspectiva, tomando para si a responsabilidade de seus atos e agindo de maneira preventiva na mudança de seu ambiente.

\section{Considerações finais}

O objetivo deste estudo foi analisar a efetividade das metodologias de intervenção social do projeto de extensão "Educação e Atenção Psicossocial a Homens Autores de Violência Conjugal" em Manaus, Amazonas, com base nos relatórios de suas atividades. Concluiuse que as metodologias foram capazes de proporcionar mudanças na compreensão dos determinantes da conduta do homem autor de violência, bem como nos modos de lidarem com os outros e consigo mesmos, de maneira que os incentivou a se implicarem em desenvolver diálogos pautados no reconhecimento e cuidado dos direitos e desejos de cada pessoa.

Essa capacidade de promover o diálogo com a parceira pode ser entendida, consoante o método interventivo, por meio da linguagem, que conseguiu ter acesso à própria construção do homem, possibilitando um espaço de reflexão que gerasse e construísse tal capacidade de dialogar.

Apesar da efetividade da metodologia interventiva desenvolvida pelos profissionais responsáveis pela condução da intervenção, os relatórios estudados evidenciaram dificuldades que tiveram de ser transpostas por eles, principalmente aquelas relacionadas às competências de outras instâncias. As necessidades encontradas relacionavam-se ao fato de a proposta ser algo inovador na região norte, bem como à carência do Estado na implementação de Redes de Apoio Social que englobassem tal problemática sob a perspectiva da assistência aos homens autores de violência que não seja pela via apenas punitiva, mas pela educativa e psicossocial.

Com a implementação dessas Redes Sociais de Apoio, a sociedade poderá usufruir de um serviço que vise contribuir para o enfrentamento dos problemas sociais encontrados pelos próprios sujeitos sociais, de maneira que não seja vista e nem receba intervenções somente por vias punitivas. O fenômeno precisa ser investigado, investido e dialogado, de forma que haja uma interlocução entre as diferentes áreas de conhecimentos em prol da resolução de tal problemática.

Por fim, enfatiza-se a importância da continuação do projeto interventivo, bem como do Serviço de Responsabilização e Educação do Agressor (SARE), uma vez que esse serviço se caracteriza como uma Rede Social de Apoio, que, por meio de uma proposta teóricometodológica inovadora na região norte, valoriza o ser social e compreende a sua construção social, possibilitando o desenvolvimento de novas potencialidades para enfrentar a violência conjugal.

Aanálise da efetividade de metodologias possibilita o questionamento dos paradigmas contemporâneos da ciência, visando refletir se objetivam contemplar a realidade em suas multidimensões e relações ou se apenas a recortam, padronizam-na e produzem verdades acerca disso. Permite, principalmente, analisar a efetividade de metodologias interventivas, oportuniza a reflexão das práticas sociais e do fazer profissional, de forma a considerar o fenômeno psicossocial em sua complexidade e dinamicidade, bem como propor à prática profissional perspectivas mais implicadas com a realidade e com os processos coletivos que demandem cada vez mais olhares pela via dialógica sobre a unidade na universalidade num caráter relacional.

\section{Referências}

ACOSTA, F.; ANDRADE, F; A., \& Bronz, (2004). Conversas homem a homem: Grupo reflexivo de gênero: metodologia. Rio de Janeiro: Instituto Noos. 
AGUIAR, L. H. M. (2011). Gênero e masculinidades: follow-up de uma Intervenção com homens autores de violência conjugal - Dissertação de Mestrado, Universidade de Brasília, Brasília, DF.

ALVES, R. F., Silva, R. P., Ernesto, M. V., Lima, A. G. B., \& Souza, F. M. (2011). Gênero e saúde: o cuidar do homem em debate. Psicologia: teoria e prática, 13(3), 152-166. Disponível em: <http:// pepsic.bvsalud.org/scielo.php ?script=sci_ arttext\&pid $=$ S15166872011000300012\&lng $>$ Acesso em 18 de Maio de 2012.

BAKHTIN, M. (1997). Estética da criação verbal São Paulo (2a ed.).: Martins Fontes.

CARVALHOSA, S. F., DOMINGOS, A., \& Sequeira, C. (2010). Modelo lógico de um programa de intervenção comunitária - GerAcções. Análise Psicológica, 28(3), 479-490. Disponível em: $<$ http://www.scielo.mec.pt/scielo.php?script $=$ sci arttext\&pid $=S 08702312010000300008 \& \operatorname{lng}=\mathrm{pt}>$ Acesso em 03 de Agosto de 2012.

CORTEZ, M. B., PADOVANI, R. C., \& Williams, L. C. A. (2005). Terapia de grupo cognitivo-comportamental com agressores conjugais. Estudos de Psicologia (Campinas), 22(1), 13-21. doi: 10.1590/S0103-166X2005000100003

DINIZ, N. M. F., LOPES, R. L. M., GESTEIRA, S. M. A., Alves, S. L. B., \& Gomes, N. P. (2003). Violência conjugal: vivências expressas em discursos masculinos. Revista da Escola de Enfermagem da USP, 37(2), 81-88. doi: 10.1590/S0080-62342003000200010

FALCKE, D., OLIVEIRA, D. Z., ROSA, L. W., \& BENTANCUR, M. (2009). Violência conjugal: um fenômeno interacional. Contextos Clínicos. Disponível em <http://pepsic.bvsalud.org/scielo.php?script=sci arttext\&pid $=$ S198334822009000200002\&lng $=$ pt $>$. Acesso em 01 de julho de 2012.

FLICK, U. (2009). Introdução à pesquisa qualitativa (3a ed., J. E. Costa, Trad.). São Paulo: Artmed.
FREIRE, P. (2008). Pedagogia da autonomia: saberes necessários à prática educativa. São Paulo: Paz e Terra.

FREITAS, R. M., \& CABRERA, O. J. (2011). Grupo reflexivo: uma alternativa de trabalho voltada aos homens. In Anais do II Simpósio Gênero e Políticas Públicas. Londrina, PR: Universidade Estadual de Londrina.

LAMOGLIA, C. V. A., \& MINAYO, M. C. S. (2009). Violência conjugal, um problema social e de saúde pública: estudo em uma delegacia do interior do Estado do Rio de Janeiro. Ciência \& Saúde Coletiva, 14(2), 595604. doi: 10.1590/S1413-81232009000200028

OLIVEIRA, P. P. (2004). A construção social da masculinidade. Belo Horizonte: EdUFMG; Rio de Janeiro: Instituto Universitário de Pesquisas do Rio de Janeiro.

PINO-SIGARDO, A. (2000). O conceito de mediação semiótica em Vygotsky e seu papel na explicação do psiquismo humano. Cadernos Cedes, 20(24), 38-59.

SANTOS, B. S. (2004). Um discurso sobre as ciências. São Paulo (2a ed.): Cortez.

SCOTT, J. W. (1988). Gender and the politics of history. New York: Columbia University Press.

SILVA, F. A., SILVA, F. P. P., TAVARES, E. S., OLIVEIRA, H. S. G., NEVES, A. L. M., SILVA, I. R., \& OLIVEIRA, K. N. L. (2015). Atenção psicossocial a homens autores de violência conjugal contra a mulher: uma construção participativa. Pesquisas e Práticas Psicossociais, 10(1), 177-190. Disponível em: <http://www.seer.ufsj.edu.br/ index.php/revista_ppp/article/view/Silva, $\% 20$ Silva, $\% 20$ Tavares, $\% 20$ Oliveira, $\% 20 \mathrm{Neves,} \% 20$ Silva, $\% 20$ Oliveira> Acesso em 27 de maio de 2012.

SMOLKA, A. L. B. (2000). Conhecimento e produção de sentidos na escola: a linguagem em foco. Cadernos Cedes.

VAUGHN, S., SCHUMM, J. S., \& SINAGUB, J. (1996). Focus group interviews in education and psychology. California: Sage Publications. 
VIGOTSKI, L. S. (1996). A formação social da mente: o desenvolvimento dos processos psicológicos superiores (5a ed.). São Paulo: Martins Fontes.

WILLIAMS, L. C. A. (2001). Violência doméstica: há o que fazer?. Sobre comportamento e cognição: expondo a variabilidade (1nd ed., pp. 1-12). Santo André, SP: ESETec.

ZURIFF, G. (1998). Against metaphysical social constructionism in psychology. Behavior and Philosophy, 26(1/2), 5-28.

Recebido em: 17/03/2017.

Aceito: 19/07/2017. 